\title{
Photographic Detection of Sub-Picomole Fluorescers by Peroxyoxalate Chemiluminescence Reaction
}

\author{
Tomohiro Uramoto, Shin'ichi Nagayama, Hironobu Matsuda, Fumio Sagara, \\ Keihei Ueno, Isao YoshIDA and Daido IsHII \\ Department of Industrial Chemistry, Kumamoto Institute of Technology, Ikeda, Kumamoto 860, Japan
}

\begin{abstract}
Femtomole fluorescers such as perylene or 5,12-bis(phenylethynyl)naphthacence (PEN) were detected photographically through the peroxyoxalate chemiluminescence reaction (CL). With the use of X-ray film, the CL emissions from 9.6X $10^{-14}$ mol fluorescers were recorded as black-and-white spots, while they are recorded as color spots on color films such as instant color films (ISO 80-100) or high speed $35 \mathrm{~mm}$ roll films (ISO 400 and 3200) with the detection limit of $9.6 \times$ $10^{-13} \mathrm{~mol}$. This technique has been applied to the detection of albumin labeled with fluorescer. As little as $0.30 \mu \mathrm{g}$ of pyrene labeled bovine serum albumin or $2.4 \mu \mathrm{g}$ of tetramethylrhodamine labeled albumin was detected by this technique.
\end{abstract}

Keywords Peroxyoxalate, chemiluminescence reaction, photographic method, perylene, 5,12-bis(phenylethynyl)naphthacene, pyrene labeled bovine serum albumin, tetramethylrhodamine labeled bovine serum albumin

Since the publication of our previous communication on the photographic detection of chemiluminescent (CL) reactants at sub-nanomole level ${ }^{1}$, the photographic detection method in $C L$ reactions has drawn keen interest because of its instrumental simplicity and versatility of the reaction. ${ }^{2,3}$ While Akiyama and his group have been interested in the photographic detection of hydrogen peroxide through peroxyoxalate $\mathrm{CL}$ reaction, our efforts have been focused on the detection of fluorescers through a similar CL reaction.

This paper describes a simple, sensitive photographic method for the detection of various fluorescers at subpicomole level. Fluorescers can be differentiated by adopting color photography, and this technique could be extended to the sensitive detection of proteins labeled with such fluorescers. As examples, this method has been applied to the detection of albumin labeled with pyrene or tetramethylrhodamine, and the CL emissions from as little as $0.3 \mu \mathrm{g}$ of albumin on a membrane filter were successfully detected by this technique.

\section{Experimental}

\section{Apparatus}

In addition to the camera luminometer which has been described in our previous paper ${ }^{1}$, a modified one which can accommodate X-ray sheet film or $35 \mathrm{~mm}$ roll film was also used in this work.

The CL reactions were carried out on a membrane filter or in a micro test tube with reflector, which is placed above the photographic film. The entire assemblies are illustrated in Fig. 1.

Polaroid 612 (ISO 20000) and 667 (ISO 3000) instant films as well as Kodak Ortho M 100 and Fuji AIF RX Xray films were used for black-and-white photographic

a)

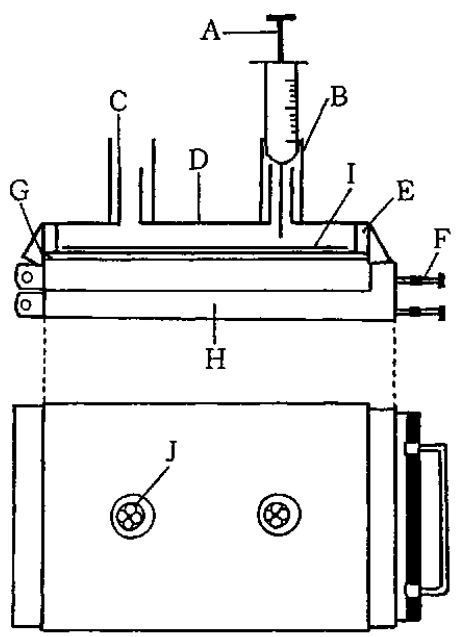

b)

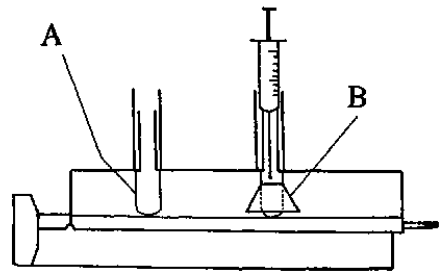

Fig. 1 Modified camera luminometer. a) Assembly for CL reaction on a membrane filter: $A$, micro syringe; $B$ and $C$, brass tubing ( $8 \mathrm{~mm}$ and $6 \mathrm{~mm}$ i.d.); D, reflector; E, spacer; F, shutter plate; G, glass plate; H, film holder; I, membrane filter; J, Teflon tubing for supporting syringe needle. b) Assembly for CL reaction in a micro test tube: A, micro test tube $(6 \mathrm{~mm}$ i.d., $0.4 \mathrm{ml}) ; \mathrm{B}$, reflector. 


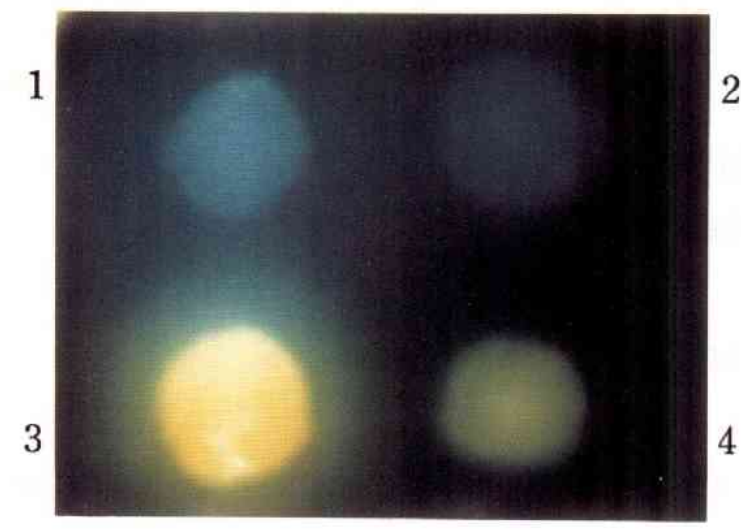

Fig. $4 \mathrm{~A}$
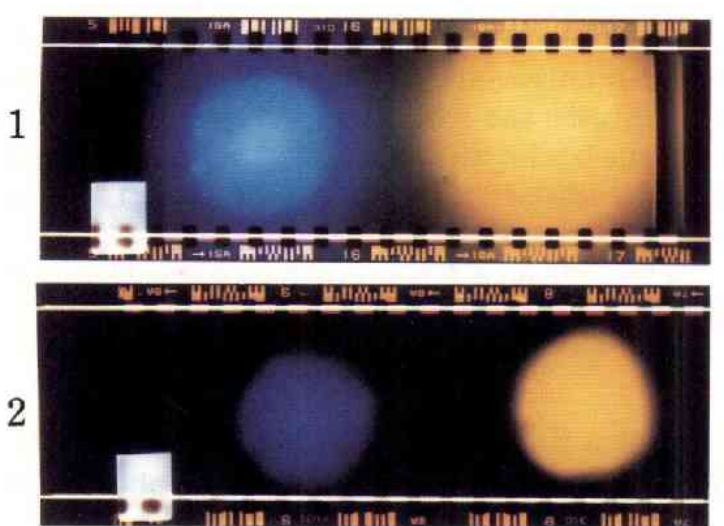

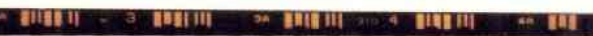

3

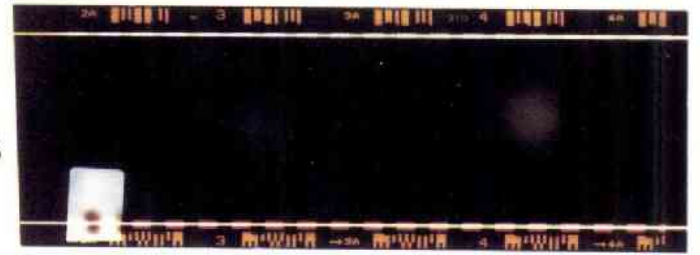

Fig. $5 \mathrm{~A}$

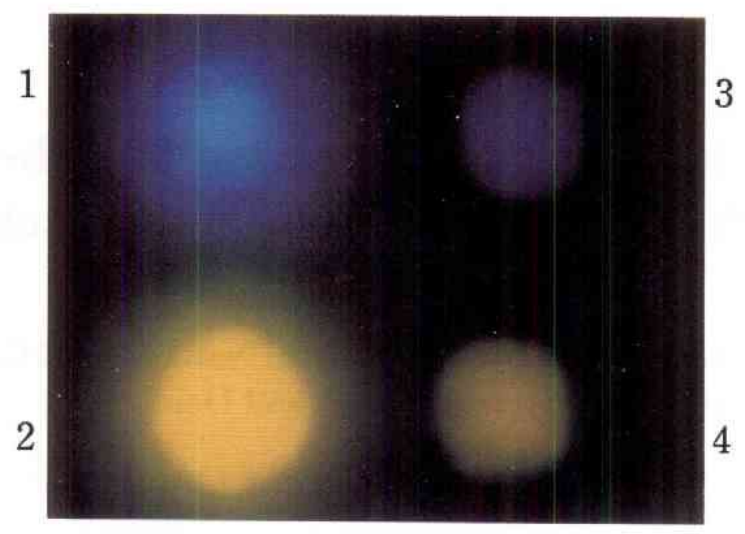

Fig. $4 \mathrm{~B}$
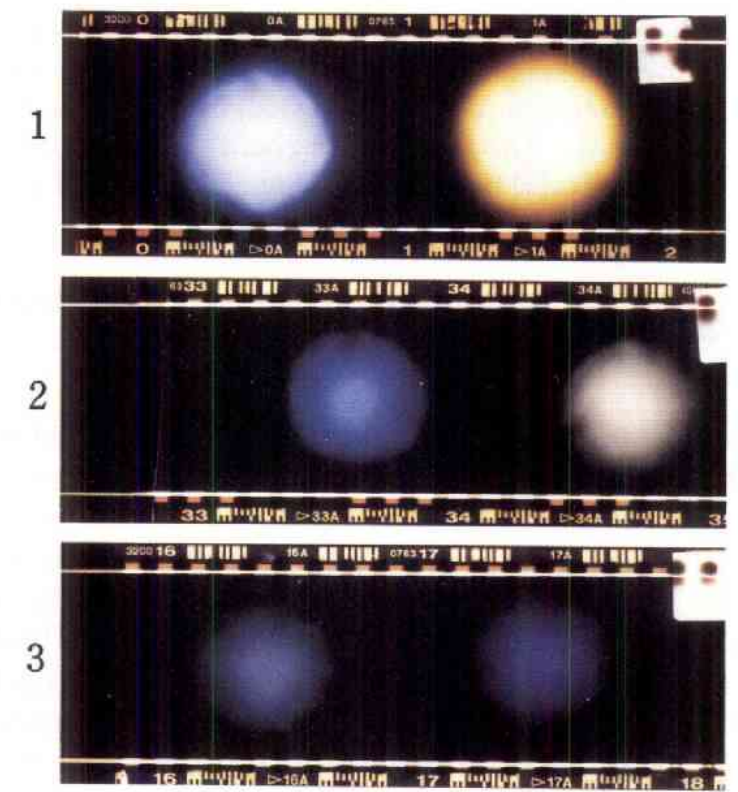

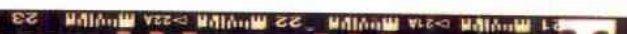

4

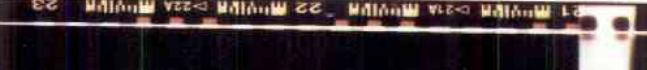

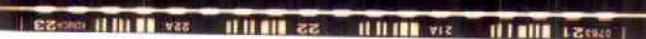

Fig. 5 B

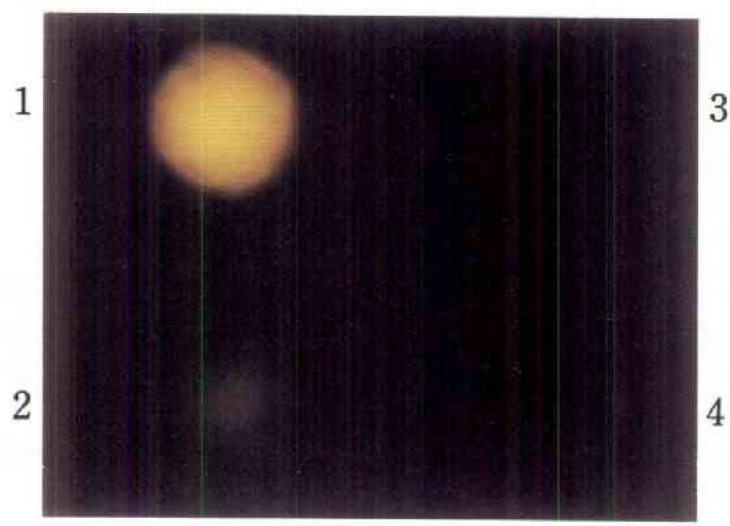

Fig. 7

Fig. 6 
Fig. 4 Photographic detection of perylene and PEN on an instant color films (Polaroid type 668 and Fuji PFC 100). A $20 \mu$ l solution containing $4.8 \times 10^{-6}$ to $\times 10^{-7} \mathrm{M}$ perylene or $\mathrm{PEN}, 0.028 \% \mathrm{H}_{2} \mathrm{O}_{2}$ and $0.44 \mathrm{M}$ imidazole buffer ( $\mathrm{pH}$ 6.0) in monoglyme was placed in a micro test tube, and a $20 \mu$ l solution of $1.0 \times 10^{-2} \mathrm{M}$ TCPO in monoglyme was dropped into it. Pictures A and B are recorded on Polaroid type 668 and Fuji PFC 100 instant color films, respectively. Spots 1 and 2 correspond to CL emissions from $4.8 \times 10^{-6}$ and $4.8 \times$ $10^{-7} \mathrm{M}$ of perylene, respectively. Spots 3 and 4 correspond to CL emission from $4.8 \times 10^{-6}$ and $4.8 \times 10^{-7} \mathrm{M}$ of PEN, respectively. Emissions from as low as $4.8 \times 10^{-8} \mathrm{M}$ fluorescers could also be detected, but only as fairly faint spots, so they are not shown in the pictures.

Fig. 5 Photographic detection of perylene and PEN on color roll films (Fuji Super GH 400 and Konica GX 3200). Experimental conditions as in Fig. 4. Pictures A are recorded on a Fuji Super HG 400 color $35 \mathrm{~mm}$ roll film (ISO 400) at the fluorescer concentrations of $4.8 \times 10^{-7}, \times 10^{-8}$ and $\times 10^{-9} \mathrm{M}$ for picture No. 1,2 and 3, respectively. Pictures B are recorded on a Konica GX 3200 color roll film (ISO 3200) at the fluorescer concentrations of $4.8 \times 10^{-7}, \times 10^{-8}, \times 10^{-9} \mathrm{M}$ and of blank for pictures No. 1, 2, 3 and 4, respectively. Blue spots are for perylene and yellow spots for PEN. Note the different color tone with different film and the noticeable blank emissions on the high speed film (Konica GX 3200) in pictures B3 and B4.

Fig. 6 Photographic detection of pyrene labeled BSA on an instant color film (Polaroid type 668). A $20 \mu \mathrm{l}$ solution containing $1.47-0.0147 \mathrm{mg} / \mathrm{ml}$ of pyrene labeled BSA in $0.44 \mathrm{M}$ imidazol buffer (pH 6.0) was spotted on a nitrocellulose membrane filter. This was placed on a camera luminometer, then $10 \mu 1$ of $6.0 \%$ hydrogen peroxide was dropped on it. After the shutter plate was opened in a dark room, $20 \mu \mathrm{l}$ of $16 \mathrm{mM}$ TCPO in 50\% monoglyme was dropped from a micro syringe. Spots 1, 2 and 3 correspond to CL emissions from $20 \mu \mathrm{l}$ of $0.0147,0.147$ and $1.47 \mathrm{mg} / \mathrm{ml}$ of pyrene labeled BSA respectively, and spot 4 corresponds to a blank.

Fig. 7 Photographic detection of tetramethylrhodamin (TMR) labeled BSA on an instant color film (Fuji PF-C100). A $20 \mu \mathrm{l}$ solution containing $1.2-0.012 \mathrm{mg} / \mathrm{ml}$ of TMR labeled BSA in water was placed in a micro test tube, then $2 \mu \mathrm{l}$ of $7.8 \%$ hydrogen peroxide in $0.44 \mathrm{M}$ imidazole buffer ( $\mathrm{pH} 6.0$ ) was dropped into it. After the shutter plate had been opened in a dark room, $20 \mu \mathrm{l}$ of $10 \mathrm{mM}$ TCPO monoglyme solution was dropped from a micro syringe. Spots 1,2, and 3 correspond to CL emmisions from $20 \mu 1$ of $1.2,0.12$ and $0.012 \mathrm{mg} / \mathrm{ml}$ of TMR labeled BSA respectively, and spot 4 corresponds to a blank.

records.

Polaroid 668 (ISO 80) and Fuji PF-C100 (ISO 100) instant films as well as Fuji Super HG 400 (ISO 400) and Konica GX 3200 (ISO 3200) (both $35 \mathrm{~mm}$ roll films) were used for color photographic records.

$\mathrm{X}$-Ray film and color roll films were processed under the standard conditions recommended by each film manufacturer.

\section{Chemicals}

Perylene (Wako) and 5,12-bis(phenylethynyl)naphthacene (PEN) (Dojindo Lab.) have been chosen as fluorescers, because of their high fluorescent quantum yield, and they were used without further purification.

Bis(2,4,6-trichlorophenyl)oxalate (TCPO) and cetylethyldimethylammonium bromide (CEDAB) are from Tokyo Kasei. All other reagents were of analytical grade, as obtained from Wako Pure Chem. Co.

\section{Preparation of pyrene labeled BSA}

BSA $(100 \mathrm{mg}, 1.54 \mu \mathrm{mol})$ was dissolved into $5 \mathrm{ml}$ $0.1 \mathrm{M}$ carbonate buffer $\left(\mathrm{NaHCO}_{3}-\mathrm{Na}_{2} \mathrm{CO}_{3}, \mathrm{pH} 9.0\right)$, to which $44 \mathrm{mg}$ (115 $\mathrm{mol}, 1.24$ fold molar excess per free amino group) of succinimidyl-1-pyrene butyrate (Molecular Probes, Eugene, OR, USA) in $200 \mu \mathrm{l}$ of
DMSO was dropped with stirring over a period of $2 \mathrm{~h}$ at room temperature. The mixture was filtered, and the filtrate was subjected to a Sephadex G10 column chromatography using pure water as an eluent. The effluent was monitored by UV detector $(280 \mathrm{~nm})$, and the protein fraction containing pyrene was collected and freeze dried to get white wools $(106 \mathrm{mg})$. The degree of labeling, as determined by absorption photometry, was found to be $95 \%$ of free amino groups.

Tetramethylrhodamine (TMR) labeled BSA was also prepared and purified in a similar fashion to that used for pyrene labeled BSA; tetramethylrhodamine isothiocyanate (Aldrich, USA) was the labeling agent. TMR labeled BSA was obtained as red-brown wools, the degree of labeling being $17 \%$.

\section{General procedure for the detection of fluorescers}

Place each $20 \mu \mathrm{l}$ solution containing $10^{-7}-10^{-9} \mathrm{M}$ fluorescer, $0.028 \%$ hydrogen peroxide, $0.05 \mathrm{M}$ imidazole buffer ( $\mathrm{pH}$ ) in water-monoglyme $(1: 10)$ on a sheet of membrane filter which is then placed above the camera luminometer in the dark room. After opening the shutter of camera, drop $20 \mu \mathrm{l}$ of $1 \times 10^{-3} \mathrm{M}$ TCPO solution in monoglyme on the filter from the microsyringe which was fixed above the membrane filter. 
Close the shutter after $90 \mathrm{~min}$, and pull out the film. In the case of $\mathrm{CL}$ reaction in a micro test tube, replace the membrane filter with the test tubes $(6.0 \mathrm{~mm}$ i.d., $0.4 \mathrm{ml})$; the rest of the procedure will be exactly the same.

\section{Results and Discussion}

Evaluation of X-ray film as the detection device of $C L$ reaction

In our previous paper, the trace amounts of the reactants or catalysts were successfully detected on a high speed instant photographic film through the CL reaction on a membrane filter or on an agarose gel plate. While the high speed instant film such as Polaroid Type 612 (ISO 20000) is a very convenient tool to detect the weak CL emission, it is one of the strategic materials in the United States and is not always easily available in our country. As a substitute for Polaroid Type 612 film, commercially available $\mathrm{X}$-ray films were evaluated as a detecting tool for $\mathrm{CL}$ emissions. The $\mathrm{CL}$ reactions chosen in this study are those of bis(2,4,6-trichlorophenyl)oxalate with hydrogen peroxide in the presence of fluorescers such as perylene or 5,12-bis(phenylethynyl)naphthacene (PEN).

Two types of X-ray film (Kodak Ortho M 100 and Fuji AIF RX) were evaluated in our work, both films being processed according to the conditions recommended by each manufacturer. Before the photographic detection of $\mathrm{CL}$ emission, the peroxyoxalate $\mathrm{CL}$ reaction was optimized with respect to the solvent system, the reactants concentrations and $\mathrm{pH}$ of the reaction. A solution of TCPO was dropped from a micro syringe into a solution of the fluorescer and hydrogen peroxide in a buffer solution which was placed in a micro test tube or on a membrane filter. Since TCPO is not soluble in water but is soluble in organic solvents, the solution has to be mixed well with the aqueous buffer solution

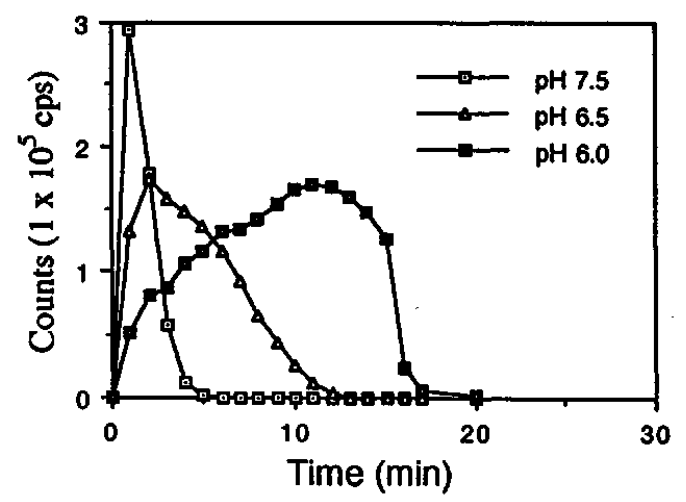

Fig. $2 \mathrm{CL}$ emission intensity at different pH. A $20 \mu \mathrm{l}$ solution of $1 \times 10^{-3} \mathrm{M}$ TCPO solution in MIBK-acetone (4/1) at $\mathrm{pH} 6.0-7.5$, was dropped into a $20 \mu$ l solution of $4.8 \times$ $10^{-10} \mathrm{M}$ perylene and $0.028 \%$ of hydrogen peroxide in $0.05 \mathrm{M}$ imidazole buffer in MIBK-acetone (2/3). The emitted photons were counted every $10 \mathrm{~s}$ and accumulated for $1200 \mathrm{~s}$ with a Hamamatsu Photonics photon-counter (C-1230). containing the fluorescer and hydrogen peroxide. Thus, the solvents for TCPO have to be miscible with water. While a mixture of MIBK-acetone was employed in the earlier part of this work, monoglyme (1,2-dimethoxyethane) was preferred in this work because of its relatively higher boiling point.

The $\mathrm{pH}$ of peroxyoxalate reaction was found to be rather important, and the CL reactions with perylene was carried out at $\mathrm{pH} 6.0,6.5$ and 7.5. The CL emissions were recorded on X-ray film and were also observed by a photon counter. The results of photon counting at various pH values are illustrated in Fig. 2. At pH 7.5, the CL emission is instantaneous. The duration of CL emission became longer with decreasing $\mathrm{pH}$ value. On the other hand, photographic spots were most prominent at $\mathrm{pH} 6.0$ and became weaker with increasing $\mathrm{pH}$ value. The result indicated that in the case of photographic detection, the peroxyoxalate $\mathrm{CL}$ emissions were most effectively recorded at $\mathrm{pH} 6.0$, while in the case of photon counting method, the preferred $\mathrm{pH}$ value is 7.5 .

Thus, in this work, $20 \mu$ l solution of $1 \times 10^{-3} \mathrm{M}$ TCPO in monoglyme was dropped into a $20 \mu \mathrm{l}$ solution containing $4.8 \times 10^{-7}-10^{-9} \mathrm{M}$ fluorescer and $0.028 \%$ of hydrogen peroxide in $0.05 \mathrm{M}$ imidazole buffer of $\mathrm{pH} 6.0$, either in a micro test tube or on a membrane filter. For example, the CL reactions were carried out on a Teflon membrane filter (Sartorius, pore size $3 \mu \mathrm{m}$ ) at $\mathrm{pH} 6$ (0.05 $\mathrm{M}$ imidazole buffer) using a MIBK-acetone mixed solvent.

Typical results are reproduced in Fig. 3. Spots are more prominent on a Fuji AIF RX film than on a Kodak Ortho film, however the differences of CL spot intensities may be due to the mismatching of wavelength of maximum film sensitivity against the wavelength of maximum fluorescence intensity of the fluorescers $\left(\lambda_{\mathrm{em}}\right.$ for perylene: $438 \mathrm{~nm}$, for PEN: $556 \mathrm{~nm}$ ), rather than to film sensitivities. As low as $4.8 \times 10^{-9} \mathrm{M}$ of perylene or PEN (20 $\mu$ l of solution corresponds to $9.6 \times 10^{-14} \mathrm{~mol}$ of perylene or PEN) could be detected on a membrane filter with the use of X-ray film. The detection limit was found to be higher by one order of magnitude than those obtained with the use of Polaroid Type 612 (4.8X $\left.10^{-10} \mathrm{M}\right)$.

\section{Detection of $C L$ emission by color film}

One of the characteristic features of the peroxyoxalate CL reaction is a wide range of emission wavelengths which can be modulated by selecting the fluorescers. For example, CL emission can be observed at $438 \mathrm{~nm}$ with the use of perylene, and at $556 \mathrm{~nm}$ with the use of PEN. Then, the CL emissions at different wavelengths could be detected with the use of color film.

The peroxyoxalate $\mathrm{CL}$ reactions were carried out either on a membrane filter (Sartorius, Nylon, pore size $0.45 \mu \mathrm{m}$ ) or in a micro test tube $(6.0 \mathrm{~mm}$ i.d., $0.4 \mathrm{ml})$. Monoglyme was chosen as a water miscible solvent for the fluorescers and TCPO. Typical results are reproduced in Fig. 4A; here the CL reactions were carried out in a micro test tube, and the emissions were recorded 

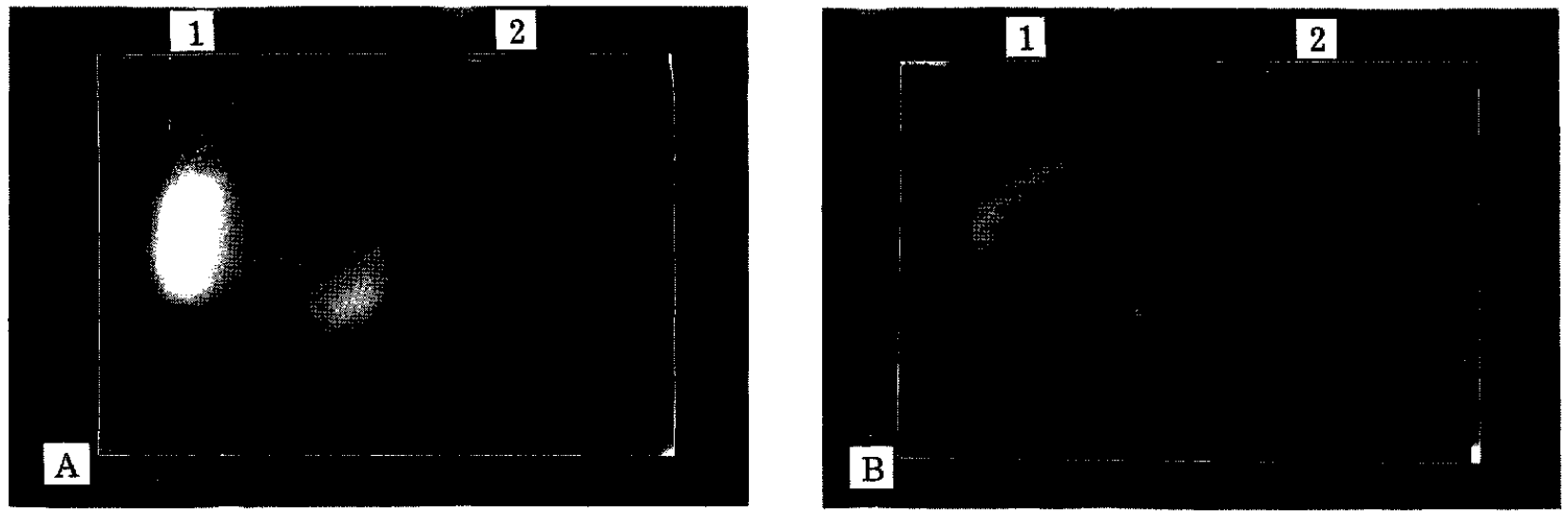

Fig. 3 Photographic detection of perylene and PEN on X-ray film (Fuji AIF RX). To a $20 \mu$ solution containing $4.8 \times 10^{-8}$ to $\times 10^{-9} \mathrm{M}$ perylene or PEN, $0.028 \%$ hydrogen peroxide and $0.05 \mathrm{M}$ imidazole buffer (pH 6.0) in MIBK-acetone (2/3), which was dropped onto a membrane filter, a $20 \mu$ l solution of $1.0 \times 10^{-3} \mathrm{M}$ TCPO in MIBK-acetone (4/1) was dropped from a micro syringe in a dark room. Pictures $\mathrm{A}$ and $\mathrm{B}$ show spots from fluorescer concentration of $4.8 \times 10^{-8} \mathrm{M}$, and $4.8 \times 10^{-9} \mathrm{M}$, respectively. Spots 1 and 2 are for perylene and PEN, respectively.

on a Polaroid Type 668 color film. It is seen from this picture that $4.8 \times 10^{-7} \mathrm{M}$ of perylene or PEN could be clearly detected and the fluorescers could be differentiated by their colors (perylene: blue; PEN: yellow-green). This is a rather unexpected result if one recalls that the film speed is only ISO 80 . The detection limits were found to be as low as $4.8 \times 10^{-8} \mathrm{M}$ for both fluorescers. When the $\mathrm{CL}$ reactions were carried out on a membrane filter, the detection sensitivity decreased one order of magnitude, i.e., to $4.8 \times 10^{-7} \mathrm{M}$ level. Similar results were obtained with the use of Fuji PF-C100 instant color film (ISO 100), however, the spots were more brilliant in colors, as illustrated in Fig. 4B.

Commercially available $35 \mathrm{~mm}$ color roll films such as Fuji Super HG 400 (ISO 400) and Konica 3200 (ISO 3200 ) which are of higher sensitivity than the conventional instant color films, were also evaluated as the detection tool for CL emissions. Films are cut in $10 \mathrm{~cm}$ lengths and a strip was placed in the film holder (Mamiya RB 67) of the luminometer. Typical results are reproduced in Fig. 5, where CL reactions were carried out in a micro test tube, and the emissions were recorded on either on a Fuji HG 400 or on a Konica GX 3200 film at the fuorescer concentrations of $4.8 \times 10^{-7}-10^{-9} \mathrm{M}$. In the case of Fuji HG 400 , spots at as low as $4.8 \times 10^{-8} \mathrm{M}$ of fluorescers could be detected with their characteristic colors. However, in the case of Konica GX 3200, blue spots are recorded at the fluorescer concentrations less than $4.8 \times 10^{-9} \mathrm{M}$ level, indicating the possibility of blank emission. It should be noted that the spots from $4.8 \times 10^{-9} \mathrm{M}$ perylene could hardly be differentiated from the blank emission (Fig. 5B, No. 3 and 4). Such blank emission could not be eliminated even after the careful purification of monoglyme.

When the CL reactions were carried out on a membrane filter, the blank emissions became more pronounced and interfered with the detection of weak emissions at $10^{-8} \mathrm{M}$ level or lower concentrations of the fluorescers. Our efforts to eliminate the blank emission by washing the membrane filter with aqueous mineral acids or aqueous EDTA, or extracting the filter with organic solvents in a Soxhlet extractor, were all unsuccessful.

Thus, the best result was obtained when the CL reactions were carried out in a micro test tube and the $\mathrm{CL}$ emissions were recorded on a Fuji HG 400 roll film, where the fluorescers in different colors were detected clearly at as low as $4.8 \times 10^{-8} \mathrm{M}(20 \mu \mathrm{l}$ of the solution corresponds to $9.6 \times 10^{-13} \mathrm{~mol}$ of perylene or PEN).

\section{Detection of fluorescer labeled albumins}

Finally, in order to evaluate the usefulness of this method to the detection of trace amounts of biopolymers, bovine serum albumin (BSA) was labeled with various fluorescers, such as pyrene, (succinimidyl-1-pyrenebutyrate as a labeling agent), coumarine (7-diethylaminocoumarin-3-carboxylic acid, succinimidylester), tetramethylrhodamine (tetramethylrhodamine isothiocyanate) and Texas Red. However, the BSA with a relatively higher degree of labeling are obtained only for pyrene (95\%) and for tetramethylrhodamine (TMR) (17\%).

Thus, the photographic detections of BSA labeled with pyrene or TMR were carried out using this technique. BSA labeled with pyrene was detected as a CL spot on a nitrocellulose membrame filter using an instant color film. As illustrated in Fig. 6, as small as $0.30 \mu \mathrm{g}$ or $3.4 \mathrm{pmol}$ of pyrene labeled BSA per spot could be detected as a blue faint spot (spot No. 1). In the case of TMR labeled BSA, CL reactions were carried out in a micro test tube, and the CL emissions were recorded on an instant color film. As illustrated in Fig. 7, as little as $2.4 \mu \mathrm{g}$ or $34 \mathrm{pmol}$ of TMR labeled BSA per spot could be detected as a yellow brown spot (spot No. 2). 
A part of the expenses of this work was defrayed from a grant-in-aid by Dojindo Laboratories, to whom the authors' thanks are due. We are also grateful to Dr. Kazumi Sasamoto of Dojindo Labs. for his technical adivices on the preparation of fluorescer labeled albumins.

\section{References}

1. K. Ueno, F. Sagara, I. Yoshida, H. Enami, S. Etho, H.
Miyazaki, A. Sonoda and M. Saito, Anal. Sci., 4, 477 (1988).

2. K. Sasamoto and Y. Ohkura, Chem. Pharm. Bull., 38, 1323 (1990).

3. K. Nakashima, S. Kawaguchi, R. S. Givens and S. Akiyama, Anal. Sci., 6, 833 (1990).

(Received November 21, 1991) (Accepted January 22, 1992) 